\title{
Penetrating the Surface: The Impact of Visual Format on Readers' Affective Responses to Authentic Foreign Language Texts
}

\author{
Ian Maun \\ School of Education and Lifelong Learning, University of Exeter, UK
}

This paper examines visual and affective factors involved in the reading of foreign language texts. It draws on the results of a pilot study among students of post-compulsory school stage studying French in England. Through a detailed analysis of students' reactions to texts, it demonstrates that the use of 'authentic' documents under currently held notions of 'authenticity' may have a negative affective impact on learners. Authors and designers of texts make assumptions about an original, intended readership which influence visual design, assumptions which are not necessarily borne out in the foreign language learning situation. There is a need to examine texts for their format as well as their content, to move away from equating 'authentic' with 'identical' and to using electronic design to improve readability.

Keywords: text, design, authentic, anxiety, readability

\section{Introduction}

The study of Modern Foreign Languages in England at the present time is at a crossroads. Language teachers are faced with Government policies on language which are both conflicting and confusing. The UK Government is pledged to raise standards in foreign language learning in England, and to this end has introduced Languages for All: Languages for Life - A Strategy for England (Department for Education and Skills, 2002). Under this initiative, all pupils must have entitlement to learn a language in Key Stage 2 (Years 3-6, ages 7-11) by 2010. It has furthermore introduced the Framework for Language Teaching in Key Stage 3 for Years 7-9, (ages 12-14), an advisory document that advocates an objectivedriven approach to language learning (Department for Education and Skills, 2003). At the same time, however, language learning has ceased to be a compulsory element of the National Curriculum in Key Stage 4 (Years 10-11, ages 15-16). Examination Boards also report reductions in the numbers of students entering language examinations at all levels (General Certificate of Secondary Education, taken at age 16, Advanced Supplementary, normally taken at age 17, and Advanced Level, taken at age 18). Meanwhile, the sometime Secretary for Education, Charles Clarke, has expressed the wish to see greater international links for all schools and a greater interest in language and culture. (The future is Mandarin, Times Educational Supplement, 12 November 2004).

Language teaching and language learning are therefore in a situation of uncertainty. The UK Government wishes to see standards raised, but its target audi- 
ence shows little enthusiasm, as many students see language learning as difficult. This leads to a lowering of motivation. (Williams \& Burden, 1999; Williams et al., 2004). The Government, however, sees dissemination of 'good practice' as the way to interest students in language and to raise standards. The official discourse of 'good practice' is enshrined in such documents as The National Curriculum for England (Department for Education and Employment, 1999), the above-mentioned Framework (Department for Education and Skills, 2003) and the specifications of the Examinations Boards.

Among the beliefs demonstrated by official bodies in their publications, such as the Department for Education and Skills, the inspecting body, known as OfSTED (Office for Standards in Education), and the Qualifications and Curriculum Authority, is the tenet that the use of authentic texts constitutes good practice. The use of authentic materials - 'language used by native speakers outside the classroom' (Day \& Bamford, 1998) - has been advocated since the 1970s as a means of bringing the target language to learners. Language teachers in England live with what has been called 'the cult of authenticity', and students are often faced with texts from target-language magazines, newspapers and leaflets, photocopied from the originals or reprinted in textbooks. Advice on teaching with such materials is not in short supply (e.g. Turner, 1998, 2001), but fundamental questions remain to be answered.

This paper will attempt to show that, far from solving the issue of converting 'input' into 'intake' (Skehan, 1998), of increasing language performance and of solving problems of motivation, reading authentic paper-printed texts may bring its own cognitive and affective problems. Such problems can only be resolved if the nature of 'authenticity' is better understood and if measures are taken to reduce the barriers of affectivity. An important question of language awareness is involved here. If teachers are aware of the problems associated with the visual aspects of 'authentic' texts, then they may be well placed to take the necessary measures to assist learning. Similarly, if students are aware that visual factors can cause an emotional reaction to text, they may well be able to 'see through' the formatting and engage with the meaning of texts whose format has not been modified by teachers to assist them.

\section{Reading and the Target Language}

Reading is the creation of meaning from marks on a page which leads to the reader's being inducted into a shared consciousness through which he/she participates in the writer's world. It plays an important role in the learning of a foreign language, at least in literate societies. While language may be learned purely orally, written materials in the literate society provide input to fuel the learner's spoken and written language. Now, 'reading and writing must be something the child needs' (Vygotsky, 1978). As Nuttall in her classic study of reading in a foreign language notes: 'If your students have no need to use the FL outside the classroom, then the only function of the FL for them seems to be: to be learnt. This is sterile and self-defeating and we ought not to be surprised if student motivation is low' (Nuttall, 1982). However, reading in FL differs from reading in $\mathrm{L} 1$, in that reading in FL is not only a way of using the target language, it is one way of initially acquiring the language system, not merely, as in L1, 
improving one's knowledge and skill in a linguistic system which is already acquired in its essentials before reading ever begins.

Reading in L1 will, of course, give access to new lexis and syntax, but this is layered on a foundation of native oral fluency which is normally lacking in the FL student. Since natural, spoken language is one of the sources of acquisition of the first language, it has become a pedagogical doctrine that the learner of a foreign language should be exposed to 'authentic' language. This notion has been extended to written texts as well as spoken discourse. This requirement is a matter of common sense, rather than of missionary dogma, according to Urquhart and Weir (1998). That this is almost a 'given' in the world of FL teaching is demonstrated by the fact that no article in Language Learning or the Language Learning Journal has featured authenticity as a principal topic for the last 10 years (1995-2005), and only one in the Modern Language Journal (Maxim, 2002).

\section{Authenticity: What Is It?}

In its classic form, the doctrine of authenticity means that readers must be exposed to texts in which nothing has been changed in either content or appearance (Grellet, 1982). Maxim (2002) defines authenticity as 'materials written to be read by native speakers of the language rather than written only to teach language'. Similarly, Demari (2004) believes that any meaning-bearing document (written, audio-visual or virtual) originally written in the target language and which is presented in class without any modifications is authentic. This belief is based on the idea that authenticity resides in the text itself. But this is far from the truth. Authenticity begins not with the text, not even with the reader, but with the writer and with the production process itself. 'How we write is shaped by the world in which we live, with cultural differences affecting not just the language we use, but also the assumptions we have about how the written text will be understood and used' (Sharples, 1999, my italics).

Hyland reinforces this: ' . . . the linguistic patterns of finished texts point to contexts beyond the page, implying a range of social constraints and choices which operate on writers in any context. The writer, then, has certain goals and intentions, certain relationships to his or her readers, and certain information to convey, and the forms of the text are resources used to accomplish these' (Hyland, 2002, my italics). The writer thus conceives of an audience to whom the text is addressed and a purpose for which his/ her writing will be used. Such an audience is essentially an artificial, mental construct in the mind of the author of a generalist text. Whereas the writer of a personal letter or email knows the destinee, the generalist or journalistic writer's audience is always a fiction (cf. Ong, 1977, 1982). Moreover, the construct of the audience may shift during the composing process (Hyland, 2002). Park (1982) focuses less on people and more on the writer's awareness of the external circumstances which define a rhetorical context and requires the text to have certain characteristics in response (my italics). The authentic text, then, is aimed at a certain audience and is shaped accordingly, both literally and metaphorically. It is unlikely, however, that learners of the language in a far-away land are ever envisaged as the intended audience of a paper-printed text. (Electronic web-pages are, of course, intended for international consumption. But that is another journal paper entirely!) 
The production process of a text, then, involves not merely envisaging an audience, but designing the text specifically for that audience. A finished, published text has, to use the terminology of Flower and Hayes (1980), been planned, translated and reviewed. That is to say, information relevant to the task has been generated, the information has been organised and the goals set (planning). These plans and ideas have been turned into text to meet goals (translating) and the text itself has been edited and evaluated, or the ideas and goals edited and evaluated (reviewing) (Sharples, 1999). It is these processes which lead to the structure and physical format of a text. The choices of font, illustration and layout are determined thus and are based on an intended audience. The degree of guidance offered to the reader (e.g. in the form of titles and section headings which give guidance to the text's macrostructure) is based upon the assumptions of the writer and the page-designer about the audience and common cultural 'givens'. Kress and van Leeuwen's comparison between the front page of the Sun and that of Bild perfectly illustrates this (1996, pp. 227-8). Such choices and guidance are not based upon the possibility of the text being used by a different audience for a different purpose. If the text is used by an envisaged audience for an envisaged purpose, then it may be considered authentic, and the design features incorporated into the production for that purpose, will, it is hoped, have a desired effect on that envisaged audience.

For Widdowson (1990): 'Authenticity in the classroom is bound to be to some extent, an illusion. This is because it does not depend on the source from which the language as an object is drawn but on the learners' [sic] engagement with it'. For Widdowson, language may be 'authenticated' by learners if it can be appropriated by them for purposes which suit their particular needs. 'Authenticity ... is achieved when the reader realizes the intentions of the writer by reference to a set of shared conventions' (Widdowson, 1980). Thus a person reading a foreign language newspaper specifically to improve their language is involved in authentic behaviour in Widdowson's eyes. This type of language behaviour, however, is somewhat secondary to the writer's and designer's original purpose for the document, and these two viewpoints of authenticity may therefore be considered rather at variance.

\section{Authenticity: What It's Not}

If an FL text is transported to the classroom for language learning purposes within that classroom, it cannot be authentic. Kawecki (2004) asserts that one of the great advantages of using 'authentic' texts is that they place the student in a real-life situation. This is not the case. If FL texts used in the classroom were truly authentic, then even in the context of language teaching, the purposes for reading them would remain authentic, and we would read menus in order to choose food to eat, railway timetables in order to catch real trains and cinema advertisements in order to choose real films to go and see. We do not. While such a text may have 'the characteristics of true discourse, having something to say, being coherent and clearly organised' (Nuttall, 1996), it has become exemplification of the target language, something other than that for which it was originally intended. It has become an 'exhibit', rather like a disused warming-pan hanging on a wall in a public house. Such materials, however, while providing examples 
of what Widdowson (1978) calls 'usage', do not provide real 'use' (i.e. meaningful communicative behaviour), since the original purpose of the materials (i.e. for the consumption by native speakers within the target culture) has been lost. At best, the learner using, say, a restaurant menu in the classroom, when no food is present, is involved in a simulation which gives an idea of what it is like to use such text in a real situation. Nevertheless, such materials, particularly in the field of reading, do provide valuable linguistic examples which learners may use and strive to imitate.

Given that FL texts are usually photocopied or reprinted (thus fulfilling Grellet's - somewhat inadequate - criteria), the best that we can say of them is that they are 'natural', i.e. they look exactly as they did in their native habitat, be it in a book, newspaper or magazine, or on a web-page, just as the warming-pan looks the same as it did when in use, but has now changed its purpose. This corresponds to Widdowson's use of the word 'genuine' to describe texts sourced directly from the target culture. Lee (1995) describes this as 'text authenticity' as against 'learner authenticity', i.e. using a text for purposes appropriate to the learner.

\section{The Intellectual and the Affective}

Devitt (1997) divides the reading process into the visual, the cognitive and the metacognitive. Reading, however, is not simply the creation of meaning through physical and intellectual activities. The emotions are also involved. 'Reading extends social, cultural and academic horizons, and is in part determined by and gives rise to affective responses to text as the reader interacts with the writer' (Davies, 1995). This aspect of reading has received little attention in the literature, writers preferring to concentrate on improving comprehension through such aspects as strategy generation (Block, 1986), vocabulary building (Laufer, 1998), gender-oriented texts (Bügel \& Buunk, 1996) or the use of dictionaries (Wingate, 2004). All of these involve operating with texts, often in their 'natural' or 'genuine' state, the aim being to produce both comprehension and identification with the culture.

However, exposure to authentic - or 'natural / genuine' - texts may give rise to negative affective reactions since, in many cases, such materials are often perceived as being 'difficult' by the learner. Now, difficulty is not an absolute property of texts. Difficulty is a relationship between a text and a reader, and what one reader finds difficult, another may find easy. Where linguistic difficulty occurs, this causes a further personal difficulty, namely that of negative affective reaction. Negative emotion has an adverse effect on readers and may ultimately destroy confidence. Day and Bamford (1998) note: 'Favorable [sic] feelings for and experiences with the teacher, class mates, materials, activities, tasks, procedures and so on, can forge positive attitudes towards reading in the second language. Unfavourable feelings and ongoing experiences can lead to negative attitudes'.

Rodriguez and Abreu (2003) reinforce this message, noting that motivation and anxiety have been found to have opposite effects on FL learners, with motivation promoting FL learning and anxiety leading to its impairment. Even at an advanced level, Vande Berg (1993) has noted that, for students of French, reading 
is indeed extremely anxiety provoking. Saito et al. (1999) conclude that 'FL reading anxiety is a specific anxiety type distinguishable from the more general types of FL anxiety that have been linked to oral performance'. It should be noted, however, that while Rodriguez and Abreu noted high reliability for their scale, they found only moderate construct validity.

\section{The Study}

The effects of readers' exposure to 'natural' texts is the subject of an ongoing study in the School of Education and Lifelong Learning at the University of Exeter.

As part of a larger study into the nature of text-difficulty in French, 122 texts were gathered from French publications of a generalist nature (e.g. recipes, news reports, explanations of everyday technology, tourist leaflets, editorials, debates, etc.), extracted principally from newspapers, magazines and publicly available leaflets. They were sorted into text-types (genres) on the basis of what was perceived by the interviewer to be their dominant purpose. This judgement was checked by a native speaker before the texts were used. Rater agreement was high. Rejected texts were replaced. A selection was made from each of five types (instructional, process, recount, description, argumentation) and two texts from each type were chosen by the interviewer. Ten Year 12 students (age 17) - a convenience sample drawn from a local Tertiary College (ages 17-18) and a local school - were shown these texts in their 'natural' state and interviewed in a pilot study to determine the factors that made such French texts difficult to understand. It was anticipated that such factors would be principally linguistic, as proved to be the case (Maun, 2005), but unexpected affective responses to formatting emerged strongly in the interviews. Linguistic factors included vocabulary, grammar, and chronological sequence or narrative. Background knowledge and familiarity with the text-type were also significant.

In sessions lasting approximately 30 minutes, students were asked to read two 'natural' texts, once each, for understanding. Each document was of a different text-type (genre). Text length varied from approximately 180 words (instructional) to approximately 4500 words (argumentative). Interviewees were asked to grade the texts immediately after reading on a scale of $1-5$, in which 1 represented 'Very Easy' and 5 represented 'Very Difficult'. Texts were presented in their original form, i.e. not photocopied. The two instructional texts (recipes) showed the finished product, the process texts had diagrammatic representations of the process. One recount text had a photograph, the other had only text. One description bore a small photograph taken in the area described, the other showed a view of the town described on the back of the text. Of the argumentative texts, one was an editorial, illustrated by a small cartoon, and the other was a text on the environment, with an idealistic photograph of a girl holding a flower in her mouth.

No comprehension test was administered after the reading. The quantitative estimate of the difficulty of the text served as a starting point for the ensuing semi-structured interviews, in which students discussed with the interviewer the aspects of the texts which led to these quantitative judgements and also discussed the general nature of printed target-language texts. The discussions 
were recorded and transcribed. A grounded theory approach (Strauss \& Corbin, 1990) was applied to the resultant data, leading to the emergence of a number of categories of response. This led to the conclusion that text-type was in part a determining factor of difficulty. These findings have been reported elsewhere (Maun, 2005). A further 22 students have since been interviewed in the ongoing study, giving further support to the original findings. These latter students came from a local Tertiary College, two single-sex grammar (i.e. selective) schools, and a private school.

The gradings given to the texts and the discussions that followed revealed grounds for believing that there may be a gradient of difficulty through the five types of text listed above, though further evidence is required to confirm such a hypothesis. Among the factors that contributed to readers' perception of difficulty was that of unknown vocabulary. This and other cognitive factors are described in Maun (2005). Affective factors, however, and quite surprisingly, also proved to have an important influence on the perception of difficulty and these form the focus of the present paper.

\section{Format factors}

Students showed affective reactions to both visual and organisational elements of text. These ranged from the size of font used to the overall macrostructure of the text. In the quotations from the interviews below, students' words and expressions which demonstrate an affective reaction (whether positive or negative) are shown in bold type. Some terms such as 'clear' and 'easy' (among others) fall between the intellectual and the emotive, but are seen as positive. Such terms are not highlighted. Neither are any terms used by the interviewer. In the quotations, 'Interviewer' is represented by ' $\mathrm{I}$ ', and the interviewee by the initial letter of his or her first name.

\section{Principles of design}

Students commented on a number of aspects of the 'languages of design'. For Sharples (1999), 'languages of design' consist typically of:

- collections of elements, e.g. shapes and styles;

- sets of organising principles, i.e. descriptions of how the elements might be composed to build up things that have meaning; and

- collections of qualifying situations, i.e. examples of how elements and principles of composition might change based on the context.

Students commented in particular on the first two, and I shall comment on the last in the conclusion.

\section{'Elements'}

Comments were made on a number of design elements. Five listed here are density, illustration, font, colour and highlighting.

\section{Density}

Text which looked generally solid, with only black and white contrast (printing against paper) produced negative reactions. Student $S$ suggested that such texts failed to produce interest: 


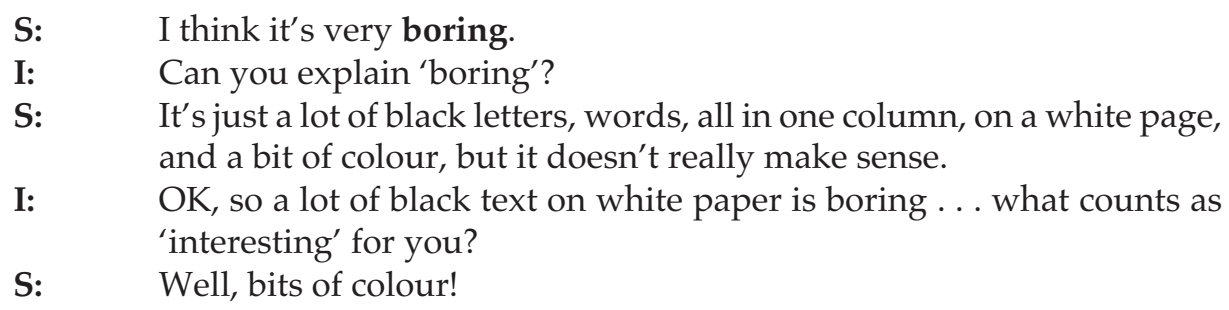

Text which bores may be demotivating. The student who is bored is not engaged with the text, is not captivated by it. This suggests that the search for meaning may well not be 'driven' and may be spasmodic. Moreover, density of black-on-white text is a 'frontal' factor, one which makes an immediate impact on the reader even before he/ she has begun to read. In a normal reading situation, such factors may affect the learner's initial decision to read.

\section{Illustration}

Illustration is not a separate element to the text but is integral to it. It forms part of 'the way in which representations and communicative acts cohere into the kind of meaningful whole we call "text"' (Kress \& Van Leeuwen, 1996). It also serves to break up a large expanse of text, as well as to illustrate or exemplify meaning (see below), and this may produce a positive effect. Student Z comments first on a text with a picture, then on solid text:

I: $\quad$ OK. What about the look of the text ... the picture ...

Z: $\quad$ Yes, that makes it a bit more appealing, with the picture, 'cause it's not just a sheet filled with writing that you have to understand.

I: Is that important, to you, as the reader?

Z: I think it is, yes, 'cause it can look a bit daunting when you've got a whole sheet of text.

I: $\quad$ Right. Tell me a bit about the word 'daunting'. Why would you feel daunted in front of a whole sheet of text?

Z: $\quad$ I suppose it's quite easy just to get bogged down by it, really, and if you see one sentence that you don't understand, it just throws you, and you just think you can't understand any of it, really.

'An attractive layout and presentation of information is often the first stage in motivating the reluctant learner to begin reading' (Mobley, 1986). The contrast in the above interview is between attraction and rejection. Illustration may draw the reader in to read the text, while density of text may produce feelings of alienation, of not being wanted as a reader. Indeed, the dense text can induce feelings of helplessness and danger:

I: $\quad$ Right. So what does a sheet filled with writing do to your confidence?

Z: $\quad$ I suppose you just think ... you just sort of drown in it, really!

Illustration, on the other hand, can be a facilitator, a key, a means of entry into the text. The impact of images may be immediate, reassuring the reader that the text has sense, making a logical link of cohesion: 
I: What about the illustration?

C: $\quad$ Yes, that helps, 'cause immediately you know what the text is about just by looking at that, I'd say, and the title.

Since the meaning of a text includes that which is conveyed by illustrations (Kress et al., 1997), the latter can make an important contribution to the reader's sense of comfort in understanding what is on the page. Unclear or irrelevant illustration may, of course, have the opposite effect.

Font

Approval is expressed for a font size which requires little effort to see and which engages by its accessibility:

S: $\quad$ What can I see? I can see a nice big title, which is catchy. I like the way it's written, the font and the size.

While differences in font size and style made some difference to students' reactions, a lengthy piece in a consistent font produced some negative emotion. As with density of text, the reader experienced a sense of rejection, and engagement with the text was not as full as it might have been had variety been present to instil a feeling of lightness and attraction:

C: $\quad$ Well, I suppose some of the writing's different sizes, which helps, and some of it's in bold - it catches your eye, the title - but really, the main bit you've got to read is all in the same kind of font and size apart from that bit there ... so that did deter you slightly from reading it.

The appearance of the font made an impact. As one student notes: 'I don't really think the font matters, but the boldness of the first text did make a small difference for some reason, to make it look more serious'. To be serious is not necessarily to be deterring. The student here implies that the text is worthy of attention. Similarly, an unusual font may be the magnet that engages the reader's attention. Another student finds a particular font appealing: 'It attracts because it's a different font, really'.

Colour

Colour has already been mentioned by students as a factor in connection with other affective elements. Comments here show that it can be of considerable importance to readers:

I: $\quad$ Is the text legible?

C: $\quad$ Yes.

I: Why is that?

C: $\quad$ Well I think again it's the colours and stuff, which make it more clear to read, and you know, you haven't got all the same colour, have you, on the text. That does make a difference, I think.

A variety of colour may not only relieve the monotony of text, it lends personality to a text, making it approachable, endearing even:

I : Were there any other factors that made it more interesting?

B: $\quad$ I think the diagram's quite sweet! With the bright colours. 
I: Do you like having bright colours in the text?

B: $\quad$ Yes, it just helps you to understand it.

\section{Highlighting}

One text used employed the device of highlighting important parts of a black-printed text in pink. The reaction was favourable:

C: $\quad$ I actually don't think I've read a text that had things highlighted like this, before.

I: $\quad$ So what's your reaction to seeing this slightly different type of text?

C: $\quad$ Well, it kind of makes you - instead of reading the whole thing, you just want to read the bits that are highlighted first.

Spotlighting a part of the text in this manner ignites the interest of this reader, making her wish to pursue those parts of the text which are emphasised in this visually engaging way. The student was motivated by the visual appearance of the text. The success of this technique of presentation is, of course, dependent to a degree on the choice of elements made by the writer or designer.

\section{'Principles'}

The organisation of text on the page is a determining factor in the reader's ability to navigate the text and to follow its rhetorical organisation. Interviewees commented on a number of 'principles' (Sharples' terminology).

\section{Columns}

Columns produced general approval, particularly as they reduced the overall impression of density (cf. the comments on density above):

I: Did the layout help you to understand?

K: $\quad$ It doesn't look as daunting as . . . I like it in columns - it doesn't look quite so bad.

I: What do you mean by 'bad'?

K: $\quad$ Scary!

I: 'Scary' - what does that mean?

K: Well, that I' $m$ not able to do it - if it looks long, it looks like harder work.

The reader's language is that of the bad experience. To be daunted is to experience anxiety, to take a step back in the face of an adversary. The dense text is not welcoming, friendly and enabling. For this student, it is 'bad', 'scary'. The text with columns may lose some of its power to produce anxiety.

Similarly:

R: I like the fact that it's in little columns - bite-size chunks.

Such 'bite-size chunks' are manageable. Such a principle of layout is an enabling factor which partially brings the target language within the control of the reader. This is contrasted with more solid text:

S: $\quad$ That [one] poses more of a threat.

I: $\quad$ A threat?!! That's interesting - tell me more.

S: $\quad$ Ijust didn't like the fact that it's got long sentences, long words, hardly 
any punctuation, so, like I said, if I don't get one thing, I generally tend not to get the other...

I: $\quad$ Right. But tell me about 'threat' - to me that means 'danger'.

S: $\quad$ It does mean danger! I was just waiting for you to ask me questions on this, 'cause I really don't get much at all, which means that I think I can't do French, or the person I'm trying to explain it to thinks I can't do French.

Here the student uses language expressive of fear of ridicule or low opinion. Indeed, the text itself is in conflict with the reader, threatening the personality by bringing about feelings of inadequacy. The text with columns produces less of a threat, reduces anxiety, leaves the personality intact. This is in accord with the definition given by Saito et al. (1999) of Foreign Language Reading Anxiety: 'The threat to an individual's self-concept caused by the inherent limitations of communicating in an imperfectly mastered second language'.

The attractiveness of columns, however, can be offset by a certain loss of sense:

I: $\quad$ That particular layout uses columns. Can you say anything about columns?

A: Ithink in this it hasn't made it easier because they've had to split quite a few of the words up.

Splitting words, of course, means splitting sense, as well as entailing further eye fixations which slow reading down, possibly below the 200-300 w.p.m. threshold required by most readers for fluent reading. (Alderson, 2000; Mobley, 1986). When reading speed falls below this threshold, the possibility arises of a loss of sense, of an inability of the working-memory to retain hold of that which it has processed while it is processing later elements.

\section{Textual sub-division}

Students who were asked about the organisation of texts responded readily, showing metacognition of macrostructure and rhetorical convention in texts. The clarity of such organisational elements served as a guide, producing positive reaction. Thus, in a tourist leaflet describing a town:

M: $\quad$ I like the way they've split all this up. It makes it nicer to read.

I: How's it split?

M: $\quad$ Into paragraphs.

I: Why do you think it's split into paragraphs?

M: $\quad$ Easier reading. So after you finish a paragraph you can move your eye for a second before you start the next.

I: Right. Do the paragraphs mark any other divisions in the text?

M: $\quad$ Separate ideas. It starts with the actual place in general and then does the main road and just progresses.

Student $\mathrm{M}$ feels affiliation with such textual division. She identifies with it ('It's nicer'), finding it user-friendly.

Student $R$ shows awareness of the paragraph as a marker of meaning-change, and thus of guidance: 
I: So what is the function in each paragraph?

R: $\quad$ To show you the general meaning of each passage - like this is about this ... this is about something else...

The monophrasal paragraph, however, can produce an adverse reaction, similar to that of textual density and undivided text. A feeling of anxiety was initially provoked in Student M:

M: $\quad$ Most of the sentences are quite long - like one of the paragraphs is just one sentence.

I: Right. Which is that?

M: [This one]

I: $\quad$ Right ... and what's the effect of seeing one long sentence?

M: It looks a bit intimidating at first, but it's all right.

I: Why does it look intimidating?

M: $\quad$ Because if you wrote it out and it had a lot of space it wouldn't look as long, but because it's only got about three words per line it looks really big.

Student $\mathrm{M}$ feels empowered by the guided layout, as it enables her to fix her attention where it is required:

I: Does the fact that it's a leaflet - so the text is separated from the pictures - have any effect?

M: $\quad$ Yeah. 'If you want to know this, read this part...'

I: $\quad$ OK. Does it make it more easy or difficult, being separated?

M: $\quad$ I think it makes it easier, because you can break it up into smaller bits and just concentrate on a tiny bit at a time.

The convention of bullet-points was also seen as a way of creating clear, defined sub-sections:

I: $\quad$ OK. The way it's laid out. Does that help you to follow what you've got to do, even if you're not sure of some of it?

A: $\quad$ Yes. The fact that it's bullet-pointed - adds like steps ...

If the author's and designer's intentions are thus made clear to the reader, this may reduce feelings of anxiety while guiding the learner towards the sense of the text through visual structural features.

\section{Titling}

Titles and sub-titles give guidance or a summary of what is to be found later in the text. Such titling may have a positive emotional effect:

I: Do you think the author was successful in guiding you through this text?

A: $\quad$ Yes, because they made it less daunting by putting it in smaller bits and having little title bits.

I: Right. When is a text 'daunting'?

A: If you are confronted with just a page of text with no breaks. Although it isn't, it looks longer. 
This accords with Zhang and Hoosain (2001), who conclude that titles facilitate the retention of detail. Their findings show that success in retention may have a positive emotional result.

Also:

R: $\quad$ It was split up nicely with a little sub-heading there.

With text features such as these, the student's burden of meaning-finding is reduced by the built-in guidance. There is one less reason to be anxious. In addition to guidance which reduces anxiety, titles and sub-titles may arouse interest:

C: $\quad$ You just read the title and you're interested and you think, 'Oh, I'm going to read that'.

The title is a trigger which might set off the reader's motivation to move on, to read the body of the text without feeling anxious or threatened. There is not only an emotional effect, but an intellectual one, in that the reader is guided towards meaning:

I: $\quad$ Did the layout of the text help you to understand it?

A: Having the little titles ... yes, it did, 'cause it gave you an idea of what the whole text was about

\section{Discussion: Emerging Dichotomies}

The purpose of reading is to create meaning in the mind of the reader. Such meaning, however, is not immediately transferable from the text to the cognitive capacities of the reader. Text takes visual form, and as such it must be 'negotiated' by the reader, that is to say, a way must be found through it to enable the reader to create meaning. Teachers expect students to engage with text in an intellectual way, as if this is an immediate and appropriate way to approach written language. The present study, however, shows readers also engaging affectively, which may produce negative reactions, possibly with the consequences outlined above by Day and Bamford (1986) and Saito et al. (1999).

The first dichotomy to emerge is thus that which exists between appearance and language. The interviewees' reactions are not always directly connected with understanding language, but relate instead to visual aspects of the text, namely to 'elements' and 'principles' of design. Some of the language employed by the interviewees (e.g. 'daunting', 'scary', 'intimidating', 'danger', 'threat') is quite extreme and non-intellectual in nature. The students are not reacting to the content of the text, but to its design, i.e. its surface, and such reactions may indeed prevent them from penetrating fully below that surface. By contrast, many of the interviewees admitted to understanding most of the text which they read. Design features were not, then, the principal obstacle to understanding (vocabulary was the most quoted factor) but some provoked anxiety, thus forming a potential barrier to total engagement and these thus served as a partial or occasional obstacle which obstructed or prevented total comprehension.

At the start of the interviews, students were asked merely to read the text and to grade it for difficulty of understanding. They were not prompted into thinking about colour, layout or any other visual aspect of the text. Therefore, it is perhaps surprising, that they were both lucid and coherent in formulating their reactions 
to the texts. Questioning by the interviewer produced immediate and well-formed responses. The affective reactions listed above were already at the forefront of the interviewees' minds. Their emotional reaction to texts was on the same plane as their intellectual reaction to its content and they could respond with equal ease to questions about both.

\section{'Elements'}

On examination, the findings with regard to the 'elements' of a text resolve themselves into a further series of dichotomies, the counter of the one factor being implicitly or explicitly (in the students' pronouncements) the other factor of the pair:

- Dense text v. light text

- Illustration v. no illustration

- Black-on-white text v. coloured text

- Colour in illustration v. no colour in illustration

- Accessible v. 'rejecting' font

Thus the fact that text which was merely dense black-on-white was felt to be 'boring' implied two counter-balances, namely that text should be lighter in its layout and contain colour. To add colour to a text is not merely to ornament it, but to make it more like the real world. Black and white is the exception in the world of reality that surrounds us, not the rule. Colour is everywhere. To impose the stark contrast of black and white on students may be to impose the unfamiliar, the unknown, the anxiety-provoking even. If reaction to such texts is negative, it is scarcely to be wondered at.

The case is similar with illustration - there is a generally positive reaction to its presence: 'It's not just a sheet filled with writing'. Note, however, that reactions to illustration are positive when the images are clear and add something to the text, but not if they are unclear or add nothing. The counter-balancing cases are implicit in the interviewees' words.

The use of particular fonts is of less importance to students, but can produce affective reactions. Size and legibility are important - 'the fact that it's big' - since they act as gatekeepers to the text, either allowing ease of access or else obliging the reader to make considerable decoding efforts before ever meaning can be accessed. The sheer 'visibility' of the print is thus a factor in permitting access to the text. There are, however, certain imponderables which are more difficult to analyse. Since some fonts are used in society in contexts which are more or less 'serious' than others, they come to have cultural connotations. Some, therefore, become associated with 'serious' contexts, others with' lighter' or 'leisure' contexts. Such a distinction is implicit in the reply of the Student B, who considered that the weight of font made the text itself seem more serious:

B : $\quad$ And the bold, I suppose, makes the text seem more formal. I did say it stood out in the beginning, but when I read that text, I'm not quite sure. I don't really think the font matters, but the boldness of the first text did make a small difference for some reason, to make it look more serious. 


\section{'Principles'}

As with the 'elements' of the text, the interviewees produced a series of dichotomies with relation to the 'principles' of the text. These dichotomies are as follows. Where one factor was given, the other was implicit or explicit in the interviewees' pronouncements.

- Columns v. solid text

- Sub-sections v. no sub-sections

- Titling v. no-titling

In the first of these dichotomies, columns relate closely to the appearance of black-and-white text, their absence combining with this colour contrast to give the impression of density. As light text is favoured by interviewees, so is the presence of columns. Indeed, it is the question of solid v. broken text which produced the most extreme emotional reactions in the survey. Such a factor may be the single most important factor in the choice of texts made by teachers if such reactions as 'scary', 'intimidating' and 'a threat' are to be avoided.

The second dichotomy is clearly illustrated by two interviewees. Firstly, an imagined dense newspaper text produces negative feelings:

K: $\quad$ I looked at that and saw three sub-sections and thought, 'That's fine. I can cope with that'. But if it was a normal newspaper page, I'd look at it and I'd think, 'No way. I can't do that'.

Likewise, Student $Z$ is at ease, precisely because the text does not exhibit those factors which may instil feelings of anxiety:

Z: $\quad$ I think what kind of made it a bit easier is it's in small sections, 'cause if you have a big text, you tend to be overwhelmed by the whole thing, whereas this was in small manageable chunks.

Finally, with regard to titles and sub-titles, it is clear that their presence may reassure and guide the reader, reassurance being an emotional matter and guidance an intellectual one.

If readers cannot approach text other than through their affective reaction to elements and principles of its layout, then there will be an indissoluble link between the appearance of a text and the degree to which readers can engage in an intellectual way with it. If emotional barriers are (unintentionally) erected by the designer of the text, then it will be necessary to find ways to access or create the meaning of a text by avoiding or surmounting those barriers.

\section{An ideal text?}

Interviewees made comments about hypothetical, non-present texts in order to highlight or compare features of the texts that they were examining. This suggests that they had some Platonic model of a text against which the present example succeeded or failed in certain aspects of visual presentation. They generally had a clear idea of the appearance of such an 'ideal' text. While they disagreed on the importance of illustration, clear organisation and a lack of density emerged as among the most important factors. What would such a text look like? 
M: It would probably be a bit longer than that, but nice and concise, and probably not as long as the other one.

I: $\quad$ Right, and what would it look like?

M: It wouldn't be set up like just in a long chunk, it'd be separated.

I: And illustrations?

M: A few, but not too many, so as not to confuse you.

I: $\quad \mathrm{OK}-$ so can you give me a number?

M: $\quad$ Three? Depends on the size of the text.

Student Z's views are similar:

Z: $\quad$ Probably split up into - like - bullet points or paragraphs, so you know when you've come to the end of one topic and you're moving on to the next. It means you don't get completely muddled up in it.

I: $\quad$ OK. Does your ideal text have to have illustrations?

Z: $\quad$ Not necessarily, no. I mean the illustration does kind of help in this way... I mean, if you had no idea what you were making, at least you'd have some kind of idea ... but not necessarily, I don't think. As long as it's in quite manageable chunks.

It is important to note that these interviewees are holding up the format of a real text against an imagined one for comparison. They are bringing to the surface emotions relating to a possible text containing features which they instinctively (through experience?) reject. No such ideal text without negatively affective factors exists, of course, but these students are so conscious of the factors which go towards the non-ideal text, with its threatening and demotivating appearance, that they are able to extrapolate from 'good' texts to one which incorporates many elements which induce positive affect and hence motivation.

\section{Conclusion}

Texts taken from the culture of the target-language exemplify aspects of that culture but by their nature are not intended for use by foreign learners. Inherent within such texts are the writer's and designer's cultural assumptions, and the 'natural' text that they produce makes no allowance for the language-learner (How could they?). Students' reactions to such 'natural' texts are not merely intellectual, but also affective, sometimes negatively so. Emotion cannot be divorced from learning. 'Affect may influence cognition through its roles in framing a problem and in adopting processing strategies' (Schumann, 1997). Schumann also points out that it is the normal case for there to be highly individual affective trajectories in second language acquisition. Hence the varied reactions to different aspects of text.

The nature of the reactions of the interviewees in this project is such as to show that far from automatically engaging with 'authentic' texts, learners are sometimes intimidated by them or even deterred from reading them. Certain text features form part of a learning context which, in the terminology of Williams and Burden (1999), is both external and uncontrollable. If learners are to commit themselves wholeheartedly in both an affective and an intellectual way, then texts must be chosen that incorporate both 'elements' and 'principles' that reduce 
the negative and emotional effects on the reader and which bring the text under the control of the reader,

Once it is understood that 'authenticity' is an impossible goal, since the text-use is different from that for which the text was written and designed, the way is open for teachers and other mediators to move away from the photocopier and to employ the computer to add design features such as colour, illustration, headings and sub-sections, and to alter original features such as unusual fonts or solid text. This is to take heed of Sharples' third category, 'situations', in which 'the elements and principles of composition may change based on the context'. (My italics). The context of language learning is different from that of native language-use within the given cultures, and such modifications are therefore justified in the design of texts for language-learners.

Official bodies such as those cited above (e.g. DfES, OfSTED) need to understand that 'authentic' cannot merely mean 'photocopied' but must be interpreted as 'originally drawn from the target-language but with appropriate modifications'. Teachers and other mediators can then feel free to alter such texts to allow full emotional and intellectual engagement by the learner. If standards of language learning are to be raised in line with Government aspirations, then there is little point in putting doctrinal or doctrinaire barriers in the way of learners, when evidence such as that which is presented here suggests that the learners themselves know what assists them towards understanding.

\section{Correspondence}

Any correspondence should be directed to Ian Maun, School of Education and Lifelong Learning, University of Exeter, Exeter EX1 2LU, UK (i.c.maun@ exeter.ac.uk).

\section{References}

Alderson, C. (2001) Assessing Reading. Cambridge: Cambridge University Press.

Block, E. (1986) The comprehension strategies of second language readers. TESOL Quarterly 20 (3), 463-94.

Bügel, K. and Buunk, B.P. (1996) Sex differences in foreign language text comprehension: The role of interests and prior knowledge. Modern Language Journal 80 (1), 15-31.

Davies, F. (1995) Introducing Reading. Harmondsworth: Penguin.

Day, R.R. and Bamford, J. (1998) Extensive Reading in the Second Language Classroom. Cambridge: Cambridge University Press.

Demari, J-C. (2004) 'Authentique', mode d'emploi. Le français dans le monde 331, 32-33.

Devitt, S. (1997) Interacting with authentic texts: Multilayered processes. The Modern Language Journal 81 (4), 457-69.

DfEE (Department for Education and Employment) (1999) Modern Foreign Languages: The National Curriculum for England. London: DfEE.

DfES (Department for Education and Skills) (2002) Languages for All: Languages for Life - A Strategy for England. London: DfES.

DfES (Department for Education and Skills) (2003) Framework for Teaching Modern Foreign

Languages: Years 7, 8 and 9. London: DfES.

Flower, L.S. and Hayes, J.R. (1980) The dynamics of composing: Making plans and juggling constraints. In L.W. Gregg and E.R. Steinberg (eds) Cognitive Processes in Writing (pp. 30-51). Hillsdale, NJ: Lawrence Erlbaum.

Grellet, F. (1982) Developing Reading Skills: A Practical Guide to Reading Comprehension Exercises. Cambridge: Cambridge University Press.

Hyland, K. (2002) Teaching and Researching Writing. Harlow: Longman. 
Kawecki, R. (2004) De l'utilité des documents authentiques. Le français dans le monde 331, 31-2.

Kress, G. and van Leeuwen, T. (1996) Reading Images: The Grammar of Visual Design. London: Routledge.

Kress, G., Leite-García, R. and van Leeuwen, T. (1997) Discourse semiotics. In T.A. Van Dijk (ed.) Discourse as Structure and Process (pp. 257-91). London: Sage.

Laufer, B. (1998) The development of passive and active vocabulary in a second language: Same or different? Applied Linguistics 19 (2), 255-71.

Lee, W.Y. (1995) Authenticity revisited: Text authenticity and learner authenticity. ELT Journal 49 (4), 323-8.

Maun, I. (2005) A new order: Reading functionally graded texts in French. Francophonie 34, $8-15$.

Maxim, H.H. II (2002) A study into the feasibility and effects of reading extended authentic discourse in the beginning German language classroom. Modern Languages Journal 86 (1), 20-35.

Mobley, M. (1986) Readability. York: Longman/SCDC.

Nuttall, C. (1982) Teaching Reading Skills in a Foreign Language. London: Heinemann.

Nuttall, C. (1996) Teaching Reading Skills in a Foreign Language (2nd edn). London: Heinemann.

Ong, W.J. (1977) Interfaces of the World. Ithaca and London: Cornell University Press.

Ong, W.J. (1982) Orality amd Literacy. London: Methuen.

Park, D. (1982) The meaning of 'audiences'. College English 44 (4), 247-57.

QCA (Qualifications and Curriculum Authority) (2002) Modern Foreign Languages: A Scheme of Work for Keystage 3. London: Qualifications and Curriculum Authority.

Rodriguez, M. and Abreu, O. (2003) The stability of general foreign language classroom anxiety across English and French. Modern Language Journal 87 (3), 365-74.

Saito, Y., Horwitz, E.K. and Garza, T.J. (1999) Foreign language reading anxiety. Modern Language Journal 83 (2), 202-18.

Schumann, J.H. (1997) The neurobiology of affect in language. Language Learning 48 (supplement 1).

Sharples, M. (1999) How We Write: Writing as Creative Design. London: Routledge.

Skehan, P. (1998) A Cognitive Approach to Language Learning. Oxford: Oxford University Press.

Strauss, A. and Corbin, J. (1990) Basics of Qualitative Research: Grounded Theory Procedures and Techniques. London: Sage.

Turner, K. (1998) Reading: Meeting the demands of the National Curriculum. Language Learning Journal 1, 8-13.

Turner, K. (2001) The National Literacy Strategy - what's in it for modern language teachers? Language Learning Journal 24, 37-42.

Urquhart, A. and Weir, C. (1998) Reading in a Second Language: Process, Product and Practice. London: Longman.

Vande Berg, C.K. (1993) Managing learner anxiety in literature courses. French Review 67, 27-36.

Vygotsky, L. (1978) Mind in Society: The Development of Higher Psychological Processes. Cambridge, MA: Harvard University Press.

Widdowson, H. (1978) Teaching Language as Communication. Oxford: Oxford University Press.

Widdowson, H. (1980) Explorations in Applied Linguistics. Oxford: Oxford University Press.

Widdowson, H. (1990) Aspects of Language Teaching. Oxford: Oxford University Press.

Williams, M. and Burden, R. (1999) Students' developing conceptions of themselves as language learners. Modern Language Journal 83 (2), 193-201.

Williams, M., Burden, R., Poulet, G. and Maun, I. (2004) Learners' perceptions of their successes and failures in foreign language learning. Language Learning Journal 30, 19-29.

Wingate, U. (2004) Dictionary use - the need to teach strategies. Language Learning Journal $29,5-11$.

Zhang, H. and Hoosain, R. (2001) The influence of narrative text characteristics on thematic inference during reading. Journal of Research in Reading 24 (2), 173-86. 